\title{
Taxon-specific microbial growth and mortality patterns reveal distinct temporal population responses to rewetting in a California grassland soil
}

\author{
Steven J. Blazewicz ${ }^{1,2,7} \cdot$ Bruce A. Hungate $\mathbb{D}^{3,4} \cdot$ Benjamin J. Koch ${ }^{3,4} \cdot$ Erin E. Nuccio $\mathbb{D}^{2} \cdot$ Ember Morrissey $\mathbb{D}^{5} \cdot$ \\ Eoin L. Brodie $\mathbb{D}^{1,6} \cdot$ Egbert Schwartz ${ }^{3,4} \cdot$ Jennifer Pett-Ridge $\mathbb{D}^{2} \cdot$ Mary K. Firestone ${ }^{1,6}$
}

Received: 25 March 2019 / Revised: 10 February 2020 / Accepted: 17 February 2020 / Published online: 12 March 2020

This is a U.S. government work and not under copyright protection in the U.S.; foreign copyright protection may apply 2020

\begin{abstract}
Microbial activity increases after rewetting dry soil, resulting in a pulse of carbon mineralization and nutrient availability. The biogeochemical responses to wet-up are reasonably well understood and known to be microbially mediated. Yet, the population level dynamics, and the resulting changes in microbial community patterns, are not well understood as ecological phenomena. Here, we used sequencing of $16 \mathrm{~S}$ rRNA genes coupled with heavy water $\left(\mathrm{H}_{2}{ }^{18} \mathrm{O}\right)$ DNA quantitative stable isotope probing to estimate population-specific rates of growth and mortality in response to a simulated wet-up event in a California annual grassland soil. Bacterial growth and mortality responded rapidly to wet-up, within $3 \mathrm{~h}$, and continued throughout the $168 \mathrm{~h}$ incubation, with patterns of sequential growth observed at the phylum level. Of the 37 phyla detected in the prewet community, growth was found in 18 phyla while mortality was measured in 26 phyla. Rapid growth and mortality rates were measurable within $3 \mathrm{~h}$ of wet-up but had contrasting characteristics; growth at $3 \mathrm{~h}$ was dominated by select taxa within the Proteobacteria and Firmicutes, whereas mortality was taxonomically widespread. Furthermore, across the community, mortality exhibited density-independence, consistent with the indiscriminate shock resulting from dry-down and wet-up, whereas growth was density-dependent, consistent with control by competition or predation. Total aggregated growth across the community was highly correlated with total soil $\mathrm{CO}_{2}$ production. Together, these results illustrate how previously "invisible" population responses can translate quantitatively to emergent observations of ecosystem-scale biogeochemistry.
\end{abstract}

\section{Introduction}

In annual grasslands, the first rains that follow a long dry period may precede plant germination by weeks or even

Supplementary information The online version of this article (https:// doi.org/10.1038/s41396-020-0617-3) contains supplementary material, which is available to authorized users.

Steven J. Blazewicz

Blazewicz1@1lnl.gov

1 Department of Environmental Science, Policy, and Management, University of California, 137 Mulford Hall, Berkeley, CA 94720, USA

2 Physical and Life Sciences Directorate, Lawrence Livermore National Laboratory, 7000 East Ave, Livermore, CA 94550, USA

3 Center for Ecosystem Science and Society, Northern Arizona University, Flagstaff, AZ 86011, USA months, but soil microbes respond immediately [1,2]. The sudden increase in soil water potential stimulates carbon mineralization [3-5], alters nutrient cycling [6], and increases the production of reactive greenhouse gases that influence the atmosphere and climate [7]. In Mediterraneantype climates, the days following the annually occurring early autumn wet-up events are pivotal periods in the biogeochemistry of these ecosystems [2, 8-10], short periods of time that contribute disproportionately to the annual

4 Department of Biological Sciences, Northern Arizona University, Flagstaff, AZ 86011, USA

5 Division of Plant and Soil Sciences, West Virginia University, Morgantown, WV 26505, USA

6 Earth and Environmental Sciences, Lawrence Berkeley National Laboratory, 1 Cyclotron Rd. MS70A-3317, Berkeley, CA 94720, USA

7 Present address: Lawrence Livermore National Laboratory, 7000 East Ave L-231, Livermore, CA 94550, USA 
budgets of element cycling [11]. While we know that $\mathrm{C}$ and $\mathrm{N}$ transformations resulting from wet-up events are almost entirely mediated by soil microbes, we do not currently have a quantitative relationship between physiology and population ecology that underlies these reoccurring, biogeochemically-consequential events. The $\mathrm{CO}_{2}$ pulse from wet-up results from the aggregated activities of billions of microbial cells, each a member of one of thousands of populations (i.e., species or taxa), together comprising the soil microbiome. Do different populations respond to wet-up differently and do these differences frame the patterns and dimensions of these events?

It is well accepted that the enormous biodiversity of soil microbial communities is coupled to both ecological and functional diversity. Given this fact, we would predict that individual microbial populations might respond differently to the radical environmental changes caused by early autumn wet-up, resulting in differential contributions of active populations to ensuing biogeochemical fluxes. Yet, prior studies suggest wet-up sometimes elicits only modest changes in the bacterial community as measured by shifts in the relative abundances of phylogenetic marker genes (e.g., $16 \mathrm{~S}$ rRNA; $[2,12,13])$. But changes in relative abundances may be poor indicators of population responses to environmental change in some cases; if responses are proportional across populations (e.g., all populations decline by $50 \%$ ), relative abundance profiles will remain stable no matter how massive the changes in density. Changes in relative and absolute abundance can even be opposite in direction: a population whose relative abundance increases in response to environmental change may still be declining in absolute abundance, just less so than other populations in the community. Another challenge is that $16 \mathrm{~S}$ rRNA community profiles provide only a single point measurement of a dynamic community, with no direct information about rates of change over time. Changes in relative abundance are unlikely to uncover the ecological mechanisms underlying community change, because the change in relative abundance is not a direct, quantitative measure of any ecological driver of population dynamics.

Population dynamics result from a combination of growth (reproduction) and mortality, the vital rates through which population densities change over time. Estimating these rates for individual bacterial populations in complex communities has long seemed an insurmountable challenge, although recent advances in metagenomics [14, 15] and quantitative stable isotope probing (SIP) [16, 17] have allowed us to make these measurements. Growth and mortality are fundamental to the ecology and evolution of biological populations. They influence fitness [18] and much of the biology in biogeochemistry $[19,20]$ since growing organisms assimilate elements and mortality transfers elements to other parts of the food web and to nonliving element reservoirs in the environment. Rates of growth and mortality also underlie basic ecological phenomena, determining which organisms are likely to outcompete others [21], which are likely to go extinct [22], how community composition changes after disturbance [23], and the relative importance of internal processes regulating populations (e.g., density dependence [24]) vs. external environmental controls (e.g., density independence [25]). These are classical concepts in ecology, long debated in the ecology of macroscopic organisms [26], but difficult to evaluate in natural microbial communities, because of methodological challenges.

For complex microbial communities, it is not yet possible to measure a direct causal connection between the growth rates of individual taxa and their respiration rates in situ, since molecules of carbon dioxide provide no information about the identity of the organisms that produced them. Furthermore, variation in growth efficiency (the proportion of carbon allocated to biosynthesis vs. energy expended in respiration) will decouple any simplistic relationship between growth and respiration. Still, because these processes are biologically linked, quantifying the growth rates of individual bacterial populations may help inform whether organisms contribute disproportionately to soil $\mathrm{CO}_{2}$ emissions. And, quantitative relationships between growth and respiration will reveal the strength of their coupling, how they change over time, and what this means for the connection between bacterial productivity and carbon balance. The large magnitude and strong temporal dynamics of soil $\mathrm{CO}_{2}$ flux after wet-up provide a powerful ecosystem level context for investigating the population biology behind this biogeochemical phenomenon.

Measuring the growth rate of microorganisms in nature has been a persistent challenge [27]. While attempts have been made-e.g., measuring fungal or bacterial productivity using labeled substrates [28], or rRNA as an indicator of microbial growth rate or metabolic status $[29,30]$-multiple hurdles exist [31-34], and taxonomic resolution is often poor. A new technique overcomes these shortcomings and provides quantitative estimates of growth and mortality rates for individual bacterial populations. The technique begins with SIP with ${ }^{18} \mathrm{O}$-labeled water to identify growing microorganisms [35-37], relying on the universal assimilation of water-derived oxygen during DNA synthesis. The assimilation of ${ }^{18} \mathrm{O}$ increases the buoyant density of DNA, making it separable from nonlabeled DNA by centrifugation in cesium chloride. In quantitative SIP, quantitative stable isotope probing (qSIP) [17], the shift in buoyant density caused by ${ }^{18} \mathrm{O}$ assimilation is quantified for particular genes (e.g., 16S rRNA sequences) and translated to a quantitative measure of ${ }^{18} \mathrm{O}$ composition of the DNA. Using these estimates of ${ }^{18} \mathrm{O}$ incorporation into DNA, a mathematical model can be applied to estimate growth rates; similarly, the 
disappearance of unlabeled DNA to can be used to estimate rates of mortality [16, 38].

Here, we used qSIP with heavy water $\left(\mathrm{H}_{2}{ }^{18} \mathrm{O}\right)$ to quantify the growth and mortality rates of bacteria following early season wet-up of a Mediterranean grassland soil. This work builds on our previous effort to quantify growth and mortality at the community level and link dynamics with rainfall-induced $\mathrm{C}$ fluxes [38].

\section{Materials and methods}

\section{Soil collection}

Soil samples were collected from the Hopland Research and Extension Center in northern California $\left(38^{\circ} 59.5784^{\prime} \mathrm{N}\right.$, $123^{\circ} 04.0469^{\prime} \mathrm{W}$ ) at the end of the summer dry season during which there had been no measurable rain for 5 months. The site is an annual grassland with soils of the Laughlin series (the fine-loamy, mixed, mesic family of Ultic Haplexerolls) and Mediterranean climate. Additional site and soil characteristics were published previously [38]. Surface vegetation was removed and soil cores $(10 \mathrm{~cm} \times$ $10 \mathrm{~cm}$ ) were collected every meter along five $8 \mathrm{~m}$ transects. Large roots and rocks were removed and then cores from each transect were combined, homogenized in the field, and sealed in air-tight jars prior to returning to the laboratory in Berkeley, CA to prevent any increase in water potential due to higher ambient humidity. Jars were stored at room temperature in the dark until incubations were started, 1 week after collection. Soil water content of field soil was determined by drying soil to a constant weight at $105^{\circ} \mathrm{C}$.

\section{Isotope labeling incubation}

Wet-up incubations were described in detail previously [38], but briefly, triplicate samples of dry soils $(2.000 \pm 0.002 \mathrm{~g}$ with prewet soil water potential of $-38 \mathrm{MPa}$ and gravimetric soil moisture of $1.0 \pm 0.07 \%$ ) were incubated in the dark at room temperature in sterile plastic aerobic culture tubes $(17 \times 100 \mathrm{~mm})$ with $400 \mu \mathrm{l}$ heavy water $\left(97\right.$ atom $\% \mathrm{H}_{2}{ }^{18} \mathrm{O}$, Cambridge Isotope Laboratories) or natural abundance water (double-distilled $\mathrm{H}_{2} \mathrm{O}$ ) for 1 week, with harvests at five timepoints ( $\mathrm{T}=0$ (prewet soil), 3, 24, 72, $168 \mathrm{~h}$ ) for a total of 27 samples. At each harvest, soils were destructively sampled and immediately frozen in liquid nitrogen and then stored at $-80^{\circ} \mathrm{C}$.

\section{C mineralization quantification}

$\mathrm{CO}_{2}$ production was measured on parallel incubations, with three biological replicates that were not destructively sampled. Soil $(40.00 \pm 0.01 \mathrm{~g})$ was sealed in $8 \mathrm{oz}$ mason jars.
Water was added by syringe through a septum in each lid and distributed into the soil by shaking. For measurements of $\mathrm{CO}_{2}$ concentration, incubation headspace $(2 \mathrm{~mL})$ was collected with a gas tight syringe and injected directly into a Hewlett Packard HP6890 (Agilent Technologies Inc., Santa Clara, CA) gas chromatograph fitted with a Hayesep DB $100 / 120\left(1 / 16^{\prime \prime} \times 1.5 \mathrm{~m}\right)$ column which fed into a Hayesep DB $120 / 140\left(1 / 16^{\prime \prime} \times 2.0 \mathrm{~m}\right)$ column leading to a pulse discharge detector (PDD). The PDD was calibrated for $\mathrm{CO}_{2}$ using a five point-standard curve, and a single standard was analyzed hourly thereafter to correct for instrumental drift.

\section{DNA extraction and density gradient SIP}

DNA was extracted from all soil samples using a modified hot phenol extraction [39]. Two replicate extractions were conducted for each sample and then replicate DNA extracts were combined. For each extraction, soil $(0.5 \mathrm{~g} \pm 0.001 \mathrm{~g})$ was mixed with TE $(420 \mu \mathrm{l} 1 \times \mathrm{TE}), \mathrm{PO}_{4}{ }^{-3}$ buffer $(150 \mu \mathrm{l}$ $0.2 \mathrm{M}$ in $1 \mathrm{M} \mathrm{NaCl}$ ), and phenol:chloroform:isoamyl alcohol $(600 \mu \mathrm{l} 25: 24: 1)$ in lysing matrix E tubes (MP Biomedicals) and bead beat $(30 \mathrm{~s}$ at $5.5 \mathrm{~m} / \mathrm{s})$. Tubes were incubated at $65^{\circ} \mathrm{C}$ for $10 \mathrm{~min}$, spun at $10 \mathrm{~K} \mathrm{RCF}_{\mathrm{avg}}$ for $5 \mathrm{~min}$, and then the supernatant was transferred to a clean tube. Soil was extracted a second time using TE $(220 \mu \mathrm{l} 1 \times$ $\mathrm{TE}), \mathrm{PO}_{4}{ }^{3-}$ buffer $(80 \mu \mathrm{l} 0.2 \mathrm{M}$ in $1 \mathrm{M} \mathrm{NaCl})$, vortexed for $10 \mathrm{~s}$, and spun at $10 \mathrm{~K} \mathrm{RCF}_{\mathrm{avg}}$ for $5 \mathrm{~min}$. The supernatant was combined with the first extract supernatant. Two phenol removal steps were done by adding an equal volume of chloroform:isoamyl alcohol (24:1) and centrifuging at $10 \mathrm{~K}$ $\mathrm{RCF}_{\mathrm{avg}}$ for $5 \mathrm{~min}$; after which the supernatant was transferred to a new tube. RNAase $(6.44 \mu \mathrm{l}, 10 \mathrm{mg} / \mathrm{ml})$ was added and incubated at $50{ }^{\circ} \mathrm{C}$ for $10 \mathrm{~min}$. $\mathrm{NH}_{4}+(244 \mu \mathrm{l}$ $10 \mathrm{M}$ ) was added, incubated at $4{ }^{\circ} \mathrm{C}$ for $2 \mathrm{~h}$, and spun at $16 \mathrm{~K}$ $\mathrm{RCF}_{\mathrm{avg}}$ for $15 \mathrm{~min}$. The supernatant was transferred to a new tube, $670 \mu \mathrm{l}$ isopropal was added, and tubes were spun at $20 \mathrm{~K}$ $\mathrm{RCF}_{\mathrm{avg}}$ for $20 \mathrm{~min}$. The supernantant was removed, DNA pellet was dried in a clean hood for $15 \mathrm{~min}$, and $30 \mu \mathrm{l} 1 \times \mathrm{TE}$ was added. DNA was stored at $-80^{\circ} \mathrm{C}$. Since soils were from the same site and homogenized, it was assumed that extraction efficiency was similar for all samples. However, little is known about the impacts of soil moisture on extraction efficiencies; it should be recognized that some error might be associated with our assumption. To minimize extraction differences between the prewet and wetted samples, the initial extraction buffer volume was varied slightly to result in equal (water volume):(dry soil mass) ratios for all extractions. Extraction efficiency was likely $<100 \%$, so the abundances per gram of soil, and therefore the growth or mortality rates per gram of soil, may be underestimated. Nevertheless, patterns observed for changes through time should be robust.

To measure the degree of ${ }^{18} \mathrm{O}$ incorporation in DNA, each sample was separated via isopycnic centrifugation in a 
cesium chloride density gradient. Gradients were generated by combining $4.60 \mathrm{ml} \mathrm{CsCl}$ stock $(1.885 \mathrm{~g} / \mathrm{ml}), 0.999 \mathrm{ml}$ gradient buffer $(0.1 \mathrm{~mol} / \mathrm{L}$ Tris, $0.1 \mathrm{~mol} / \mathrm{L} \mathrm{KCl}$, and $1 \mathrm{mmol} / \mathrm{L}$ EDTA), and $5.5 \mu \mathrm{g}$ DNA in $50 \mu \mathrm{l} 1 \times \mathrm{TE}$ for a final density of $1.735 \mathrm{~g} / \mathrm{ml}$. After mixing, $\sim 5.2 \mathrm{ml}$ of the solution was transferred to an ultracentrifuge tube (Beckman Coulter QuickSeal, $13 \mathrm{~mm} \times 51 \mathrm{~mm}$ ) and heat-sealed. Tubes were spun in an Optima L-90K ultracentrifuge (Beckman Coulter) using a VTi65.2 rotor at $44,000 \mathrm{rpm}\left(176,284 \mathrm{RCF}_{\text {avg }}\right)$ at $20^{\circ} \mathrm{C}$ for $109 \mathrm{~h}$ with maximum acceleration and braking.

Immediately following centrifugation, the contents of each ultracentrifuge tube was separated into $\sim 75$ fractions. To displace the gradient solution in the tube, a syringe pump was used to deliver light mineral oil at $0.25 \mathrm{ml} / \mathrm{min}$ through a $25 \mathrm{~g}$ needle inserted into the top. Tubes were mounted in a fraction recovery system (Beckman Coulter) with a side port needle inserted through the bottom as the outlet. Approximately 5 drops $(\sim 70 \mu \mathrm{l})$ were collected for each fraction. The density of each fraction was measured as previously described [40] using an AR200 digital refractometer (Reichert) fitted with a prism mask to facilitate measurement from $5 \mu \mathrm{l}$ volumes. DNA in each fraction was purified and concentrated as previously described [41] using a glycogen/ PEG precipitation followed by an ethanol wash. Each fraction was resuspended in $25 \mu \mathrm{l} 1 \mathrm{x}$ TE and stored at $-80^{\circ} \mathrm{C}$.

All fractions were analyzed for total DNA content via a picogreen fluorescence assay. The fractions were binned into three groups based on density for each sample (Light $=$ $1.680-1.7259 \mathrm{~g} / \mathrm{ml}$, Middle $=1.726-1.7419 \mathrm{~g} / \mathrm{ml}$, Heavy $=$ $1.7420-1.775 \mathrm{~g} / \mathrm{ml}$; average density values used for qSIP were Light $=1.7025$, Middle $=1.7320$, Heavy $=$ $1.7575 \mathrm{~g} / \mathrm{ml}$ ). The binned fractions were combined, and the DNA was precipitated and suspended in equal volumes. The condensed fractions were analyzed for total DNA content with picogreen.

\section{Quantitative PCR}

Total bacterial 16S rRNA gene copies were quantified for the combined fractions using bacterial 16S qPCR (EUB338/ EUB518) as previously described [24]. All qPCR reactions were conducted with a CFX96 Real-Time PCR Detection System (Bio-Rad, USA). Samples were analyzed in triplicate with $20 \mu \mathrm{l}$ reactions containing $10 \mu \mathrm{l}$ Sso Fast Evagreen Supermix (Bio-Rad), $1 \mu \mathrm{l}$ of forward and reverse primers $(10 \mu \mathrm{M})$ (Sigma-Aldrich), $7 \mu \mathrm{l}$ PCR grade MQ-water (MP Biomedicals), and $1 \mu \mathrm{l}$ of template DNA $(6.67 \mathrm{ng} / \mu \mathrm{l})$. Plasmid standards were prepared by inserting a copy of purified PCR product from soil DNA into Escherichia coli. The E. coli was then cultured, and the plasmids were extracted, purified, and quantified. The plasmid was verified to contain appropriate inserts by sequencing. Thermocycling parameters consisted of $3 \mathrm{~min}$ at $95^{\circ} \mathrm{C}$, followed by 40 cycles of $30 \mathrm{~s}$ at $95{ }^{\circ} \mathrm{C}, 30 \mathrm{~s}$ at $53^{\circ} \mathrm{C}$, and $10 \mathrm{~s}$ at $60^{\circ} \mathrm{C}$, at which time fluorescence was measured. Following $\mathrm{qPCR}$ analysis, a melting curve was conducted from 55 to $95^{\circ} \mathrm{C}$ with an increase of $0.5^{\circ} \mathrm{C}$ every $5 \mathrm{~s}$ to ensure that results were representative of the target gene. Purity and correct targeting of amplicons were also checked by running random samples on an agarose gel to visualize qPCR products. Average PCR efficiency was $98 \%$ and average slope was -3.38 , with all standard curves having $R^{2} \geq 0.99$.

\section{Sequencing}

DNA samples were normalized to $10 \mathrm{ng}$ per reaction prior to PCR. Samples were amplified using the F515/R806 PCR primer pair targeting the V4 region of the 16S rRNA [42]. The forward and reverse primers were modified to contain an Illumina adapter region for sequencing on the Illumina GAIIx platform. The reverse PCR primer was barcoded with a 12-base error-correcting Golay code to facilitate multiplexing. PCR reactions were performed using Takara Hot Start Ex Taq polymerase (Takara, Madison, WI), with the following thermocycling parameters: initial denaturation at $98^{\circ} \mathrm{C}$ for $2 \mathrm{~min}$ followed by 30 cycles at $98^{\circ} \mathrm{C}$ for $20 \mathrm{~s}$, $30 \mathrm{~s}$ of annealing at $50^{\circ} \mathrm{C}$ and extension at $72^{\circ} \mathrm{C}$ for $45 \mathrm{~s}$. Final product extension was at $72^{\circ} \mathrm{C}$ for $10 \mathrm{~min}$. Reaction primer dimers were removed from the PCR products via SPRI bead purification according to the manufacturer's protocol (AMPure XP, Beckman Coulter Genomics, Danvers, MA) before being checked for quality and average size distribution on a Bioanalyzer 2100 using a DNA 7500 chip (Agilent Technologies, Santa Clara, CA). Cleaned amplicons were quantified using Quant-It Picogreen dsDNA reagent in $10 \mathrm{mM}$ Tris buffer (pH 8.0) (Life Technologies, Grand Island, NY). A pooled sample for sequencing was created by combining equimolar ratios of amplicons from the individual samples.

The pooled 16S rRNA gene library was diluted to $2 \mathrm{nM}$. Following $\mathrm{NaOH}$ denaturation, the libraries were applied to a v4 TruSeq Paired End GA flow cell/cluster kit (Illumina Inc., San Diego, CA) at 5pM. For clustering sequencing of read 1, index read, and read 2, custom sequencing primers (Integrated DNA Technologies, Coralville, Iowa) were used at a final concentration of $500 \mathrm{nM}$ to spike into the primers from the cluster kit. Sequencing on the GAIIx (TruSeq SBS kit v5 reagents) was done according to the manufacturer's instructions.

\section{Quality filtering of sequence reads, OTU picking, and taxonomy assignment}

Sequences were demultiplexed then trimmed using the program Trimmomatic [43]; bases were trimmed using the 
sliding window method and sequences shorter than $75 \mathrm{bp}$ were removed from the dataset. The window size was set at four base pairs, and the average Sanger quality (Q) value threshold was set at 20 [44]. Forward reads were discarded due to poor quality and only the reverse reads were used for community analysis.

Sequences were clustered using UCLUST [45] and classified using QIIME (version 1.8) at the 97\% similarity level [46]. The RDP classifier [47] was trained using the Greengenes $99 \%$ similarity $16 \mathrm{~S}$ gene rRNA database (May 2013) trimmed to the reverse section of the V4 region (E. coli positions 2489-4090) [48]. Sequences were aligned using Pynast [49] and chimeras were identified using UCHIME [50]. Pynast failures, singletons, chimeras, and sequences present in only one sample were removed from the dataset. Sequences were rarefied to 30,336 sequences per sample and aggregated at the L6 level using QIIME, which produced 615 taxonomic groups (Table S1).

\section{Quantitative stable isotope probing calculations}

We calculated taxon-specific density shifts caused by incorporation of ${ }^{18} \mathrm{O}$ into DNA following the qSIP procedures described by $[16,17]$. The mathematical model developed for qSIP estimates the shift in density for each taxon that can be attributed to ${ }^{18} \mathrm{O}$ assimilation into DNA. This shift is measured by first determining baseline densities for each taxon in the absence of an isotope tracer, because even without tracer assimilation, density varies with the GC content of the DNA [51]. Density of each taxon with the isotope tracer is then determined. The difference in measured densities - with the added ${ }^{18} \mathrm{O}$ tracer vs. without-is directly proportional to ${ }^{18} \mathrm{O}$ assimilation by individual taxa [17], a relationship that has been verified by strong correlations between density shifts and tracer uptake determined by isotope-ratio mass spectrometry (Fig. 1 in [17]). In this way, qSIP provides taxon-specific quantitative estimates of the uptake of stable isotope tracers in microbial communities.

We estimated the number of 16S rRNA gene copies per taxon in each density fraction by multiplying the sequencing-derived taxon-specific relative abundances by the total number of $16 \mathrm{~S}$ gene copies as measured by qPCR. To maximize the available information on the densities of taxa in the natural abundance isotope treatment, we combined taxon-specific density estimates across the 3, 24, 72, and $168 \mathrm{~h}$ time points for a total of 12 replicates. We limited our analyses to only those taxa that occurred in at least 3 (of 12) replicates of the natural abundance treatment and in all three replicates of the ${ }^{18} \mathrm{O}$ treatment, in order to reduce the likelihood of spurious density shifts for rare taxa. Density shifts and atom fraction excess estimates, along with 95\% confidence intervals, were computed using bootstrapping (1000 iterations; [17]). This method has been estimated to be able to detect shifts in ${ }^{18} \mathrm{O}$ assimilation by as little as 5.6 atom $\%{ }^{18} \mathrm{O}$ with $90 \%$ confidence [17].

As described previously, qSIP can be used to estimate growth rates for individual microbial populations [16], requiring estimates of $16 \mathrm{~S}$ rRNA gene abundance at the beginning and end of an experiment, and the change in ${ }^{18} \mathrm{O}$ composition of 16S rRNA genes for each taxon. The calculations rest on the premise that the rate of DNA replication is directly proportional to the growth rate of dividing cells, which is reasonable given that DNA replication is so integral to cellular division. The approach assumes that a constant proportion of oxygen in newly-formed DNA is derived from water, an assumption based on both experimental and mathematical constraints $[16,17]$. The calculations quantitatively relate increases in the abundance of a particular marker gene-in this case, the 16S rRNA geneto growth and declines in that marker gene to loss through mortality. The isotope tracer, ${ }^{18} \mathrm{O}$, makes it possible to discern changes in gene copy abundance caused by growth, assuming that all newly-formed DNA is ${ }^{18} \mathrm{O}$-labeled, and mortality, assuming that the rate of loss of DNA to mortality is independent of whether it is labeled with ${ }^{18} \mathrm{O}$ or not [16]. The model estimates per capita growth rate-a function of the rate of appearance of ${ }^{18} \mathrm{O}$-labeled 16S rRNA genes-and per capita mortality rate-estimated from the disappearance of unlabeled $16 \mathrm{~S}$ rRNA genes [16].

We estimated absolute population growth and mortality rates (\# $\mathrm{g} \mathrm{soil}^{-1} \mathrm{~d}^{-1}$ ) as the changes in $16 \mathrm{~S}$ gene copies per gram soil per time, over each of the four time intervals of the incubation: $0-3,0-24,0-72$, and $0-168$. We assumed linear population growth over the course of the incubations, and we estimated taxon-specific net absolute population growth rates for the four time intervals as:

$r_{i}=\frac{N_{\text {TOTAL } i t}-N_{\text {TOTAL } i 0}}{t}$,

where $N_{\text {TOTAL } i 0}$ and $N_{\text {TOTAL } i t}$ are the $16 \mathrm{~S}$ gene abundances of taxon $i$ at the beginning (0) and end $(t)$ of the incubation time interval, respectively, and $r_{i}$ is the net population growth rate, which is the sum of the absolute rates of reproduction $\left(b_{i}\right)$ and mortality $\left(d_{i}\right)$ :

$r_{i}=b_{i}+d_{i}$.

Abundances have units of number of $16 \mathrm{~S}$ gene copies per gram of dry soil. The absolute rate of reproduction (i.e., gross population growth) is a function of the rate of appearance of ${ }^{18} \mathrm{O}$-labeled 16S rRNA genes, and the absolute rate of mortality is estimated from the disappearance of unlabeled 16S rRNA genes [16]. Specifically, the absolute 
mortality rate of taxon, $i,\left(d_{i}\right)$ was estimated as:

$d_{i}=\frac{N_{\text {LIGHT } i t}-N_{\text {TOTAL } i 0}}{t}$,

where $N_{\text {LIGHTit }}$ is the number of unlabeled gene copies for taxon $i$ at the end of the incubation period (time $t$ ), and $N_{\text {TOTAL } i 0}$ is the number of unlabeled gene copies for taxon $i$ at the beginning of the incubation period (time 0 ). Note that at time 0 , all gene copies are unlabeled, thus, $N_{\text {TOTAL } i 0}=$ $N_{\text {LIGHTi0 }}$ [16].

Similarly, the absolute rate of reproduction for taxon $i$ $\left(b_{i}\right)$ is estimated as:

$b_{i}=\frac{N_{\mathrm{TOTAL} i t}-N_{\mathrm{LIGHT} i t}}{t}$,

where $N_{\text {TOTALit }}$ and $N_{\text {LIGHTit }}$ are the total (unlabeled + labeled) and unlabeled 16S gene abundances of taxon $i$ at the end $(t)$ of the incubation interval, respectively. $N_{\text {LIGHTit }}$ is a function of total $16 \mathrm{~S}$ gene abundance, as well as the molecular weights of unlabeled (natural abundance) DNA, ${ }^{18} \mathrm{O}$-labeled DNA, and the average molecular weight of all DNA (labeled + unlabeled) at the end of the ${ }^{18} \mathrm{O}-\mathrm{H}_{2} \mathrm{O}$ incubation (see Eq. (3) in [16]).

We also estimated per-capita population growth and mortality rates (units: day ${ }^{-1}$ ), by dividing absolute rates of reproduction $\left(b_{i}\right)$ and mortality $\left(d_{i}\right)$ by the average abundance of $16 \mathrm{~S}$ gene copies over each time interval.

We used measurements of soil moisture content to estimate the dry mass of soil represented by the DNA in each centrifuge tube. Whole-centrifuge-tube abundances were calculated as the sum across all density fractions and were expressed in units of $16 \mathrm{~S}$ gene copies/g dry soil. For the purpose of the growth calculations, we established a minimum abundance for cases where taxa were observed as absent from some, but not all, time points. This minimum abundance was set using a concentration of $8.26 \times 10^{-4} 16 \mathrm{~S}$ gene copies/ $\mu$, or one-half of the minimum number of $16 \mathrm{~S}$ gene copies detected for all taxa across all time points and isotopic treatments. The fraction of oxygen in DNA derived from water (vs. other organic sources) was assumed to be 0.60 [16]. Uncertainty of growth and mortality rates (95\% confidence interval) was estimated using a bootstrapping procedure with 1000 iterations [16]. As previously discussed [16], it is important to note that calculated absolute abundances are still approximations due to several challenges and biases involved with the end-to-end processing and analyses including incomplete extraction of DNA from free-living cells in soil [52], inter-taxonomic variation in 16S rRNA gene copies per cell, amplification and sequencing biases $[53,54]$. Due to such issues, we note that it is most robust to consider our absolute abundances as coarse estimates in measuring taxon-specific growth and death rates.
We tested the effect of population densities on rates of growth and mortality. These are classical concepts in ecology, where density dependence indicates internal regulation of populations, for example, when competition becomes more intense as population sizes increase, eventually limiting the size of the population [24]. Alternatively, external environmental factors have been proposed as being more important [25]. While both clearly occur in nature [26], their relative importance has been difficult to evaluate in natural microbial communities, because of methodological challenges; taxon-specific estimates of growth and mortality make it possible to evaluate the importance of density-dependent vs. density-independent processes in microbial communities, including in soil [16]. To test for density dependent growth and mortality, we used simple linear regression, with population density as the independent variable, and per capita growth rate or per capita mortality rate as the dependent variable. All statistical and qSIP modeling calculations were performed using the $\mathrm{R}$ programming language [55].

\section{Results}

\section{Density shift and ${ }^{18} 0$ uptake into $16 S$ rRNA}

Following the wetting of dry California grassland soil with $\mathrm{H}_{2}{ }^{18} \mathrm{O}$, and isopycnic centrifugation to distinguish isotopically enriched DNA, the density of 16S rRNA genes significantly increased over the course of a week (Figure S1). In contrast, no density shift occurred in control soils incubated with water with a natural abundance oxygen isotope composition. This pattern indicates that a substantial amount of ${ }^{18} \mathrm{O}$ was incorporated into newly synthesized DNA of growing bacteria which allowed us to use the qSIP mathematical approach to calculate both growth and mortality rates. Assessed quantitatively using qSIP, there was considerable variation in the degree of ${ }^{18} \mathrm{O}$ uptake among taxa, with a median atom fraction excess ${ }^{18} \mathrm{O}$ value of 0.091 $(0.0045 \% \mathrm{SE})$ and a maximum taxon-specific median atom fraction excess of 0.81 (95\% CI: 0.776-0.823); confidence intervals indicated cases where ${ }^{18} \mathrm{O}$ uptake was positive and others where values were indistinguishable from zero.

\section{Dynamics of growth and mortality}

Bacterial growth was detectable within the first $3 \mathrm{~h}$ after wet-up and in each measurement period thereafter (Fig. 1). At the L6 level, 615 taxonomic groups were identified in the sequence data (Table S1); 341 of these had measurable growth rates (Table S2) with 232 of these significantly greater than zero (95\% CI, Table S3). All data analyses and discussion for growing organisms use data from the 232 
a

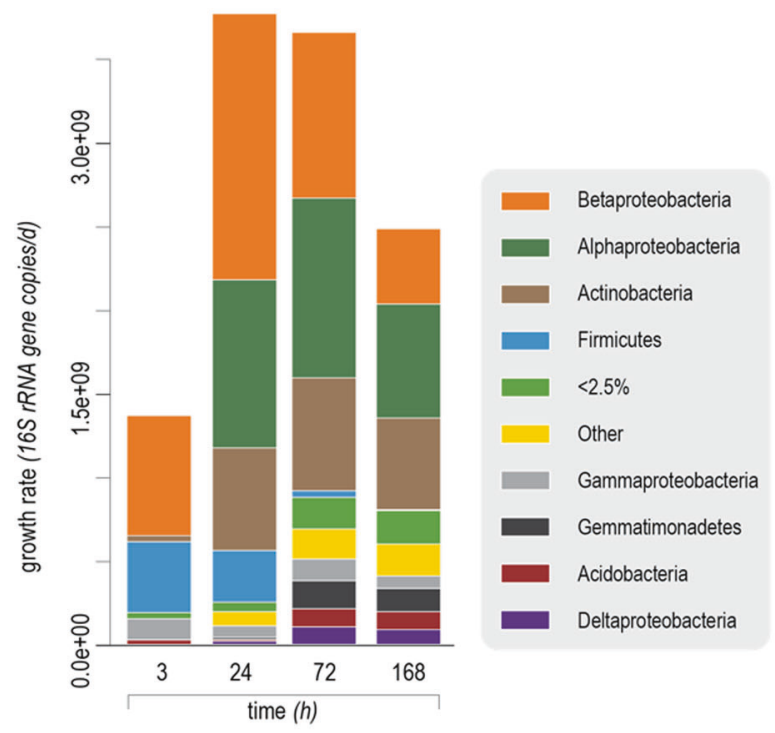

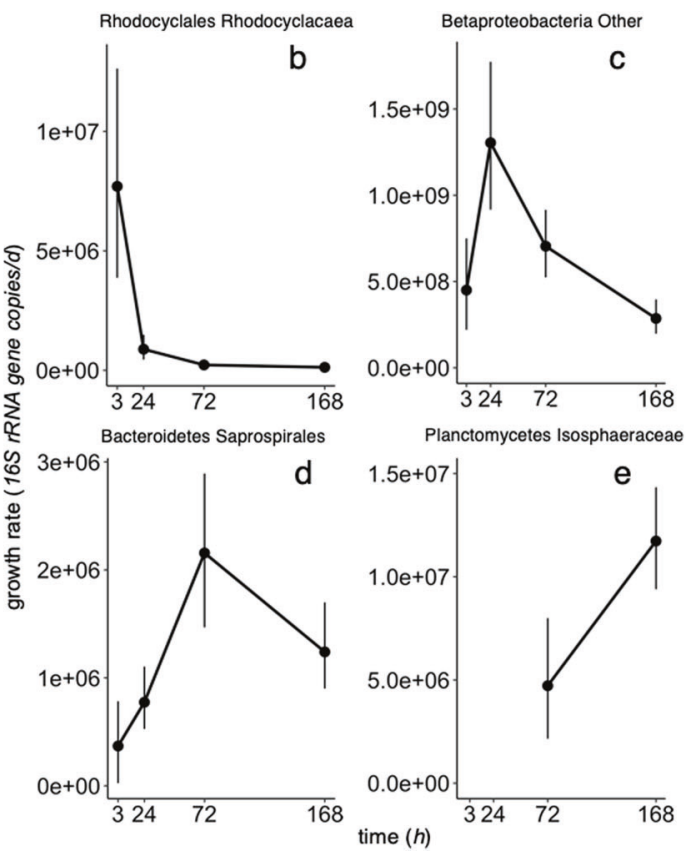

all phyla calculated to have growth rates significantly greater than zero (95\% CI). b-e Examples of growth rate response patterns (b primary, c secondary, $\mathbf{d}$ tertiary, e delayed) exhibited by four different taxa. taxa with significantly greater than zero growth rates unless otherwise stated. Summed across the entire bacterial community, the growth rate increased by $275 \%$ between 3 and $24 \mathrm{~h}$ after wet-up and then held steady through $72 \mathrm{~h}$. The growth rate $168 \mathrm{~h}$ after wet-up - the last measurement point-was $181 \%$ higher than the total growth rate measured $3 \mathrm{~h}$ after wet-up. Thus, bacterial growth began within $3 \mathrm{~h}$ of wet-up, reached its maximum rate within a day and persisted throughout the 1 week measurement period.

Mortality rates were very high within hours of wet-up and declined rapidly thereafter (Fig. 2, Table S4). The mortality rate after $24 \mathrm{~h}$ was $19 \%$ of the initial rate measured during the first $3 \mathrm{~h}, 8 \%$ of that initial rate after $72 \mathrm{~h}$, and declined to $3 \%$ of the initial rate after $168 \mathrm{~h}$. The rate of mortality always exceeded the rate of growth, though they tended to converge over time: mortality was two orders of magnitude higher than growth during the first $3 \mathrm{~h}$ after wetup, 6.8 times higher after $24 \mathrm{~h}, 2.9$ times higher after $72 \mathrm{~h}$, and 1.7 times higher after $168 \mathrm{~h}$.

\section{Taxonomic variation in growth and mortality}

The initial burst of growth in the first $3 \mathrm{~h}$ following wet-up was concentrated in specific bacterial phyla, highest in the Betaproteobacteria, the Firmicutes, and the Gammaproteobacteria, with detectable but considerably lower rates of growth in the Actinobateria, Acidobateria, and
Deltaproteobacteria (Fig. 1). Growth in the Deltaproteobacteria and in the Gemmatimonadetes were delayed with highest rates of growth observed at 72 and $168 \mathrm{~h}$. The highest observed absolute population growth rates at any of the timepoints was found in the Alphaproteobacteria $\left(1 \times 10^{9} 16 \mathrm{~S}\right.$ rRNA gene copies/g $/ g_{\text {soil }} / \mathrm{d}$ at 24 and $\left.72 \mathrm{~h}\right)$ and Betaproteobacteria $\left(1.6 \times 10^{9} \mathrm{rRNA}\right.$ gene copies $/ \mathrm{g}_{\text {soil }} / \mathrm{d}$ at $24 \mathrm{~h}$ ). Within these phyla, the growth was dominated by Rhizobiales and Sphingomonadales orders in the Alphaproteobacteria and Burkholderiales in the Betaproteobacteria. At the L6 level, the number of growing taxa with detectable positive growth steadily accumulated over time, with the largest growth diversity found at $168 \mathrm{~h}$ (Fig. 3) and growth found in 18 phyla by $168 \mathrm{~h}$. Taxa at this level also exhibited different growth rate response patterns, with growth rate curves representing four potential responses: primary, secondary, tertiary, delayed (Fig. 1b-e). As a coarse approach to categorize organisms according to these different response groups, we identified the time point with maximum growth rate for each taxon. Of the growing genera, we found $5.2 \%$ to be primary, $12.1 \%$ secondary, $34.5 \%$ tertiary, and $48.3 \%$ were delayed responders (Table $\mathrm{S} 3$ ).

While overall mortality declined over time, mortality richness was much more consistent throughout the entire incubation (Fig. 3), in contrast to growth. Also in contrast to growth, mortality rate response patterns were similar for almost all taxa (Fig. 2b, c) 
Fig. 2 Absolute population mortality rates for bacteria following wet-up of dry soil. a Average phylum level mortality rates (significant at 95\% CI) measured over the course of a week. b, c Examples of individual taxa with the most common mortality response pattern. By convention, mortality rates are expressed as negative values.
Fig. 3 Growth and mortality richness through time.

a Number of bacterial taxa with detectable positive growth rates, measured at four timepoints following wet-up of a dry CA annual grassland soil. b Number of taxa with detectable mortality following wet-up of a dry CA annual grassland soil.
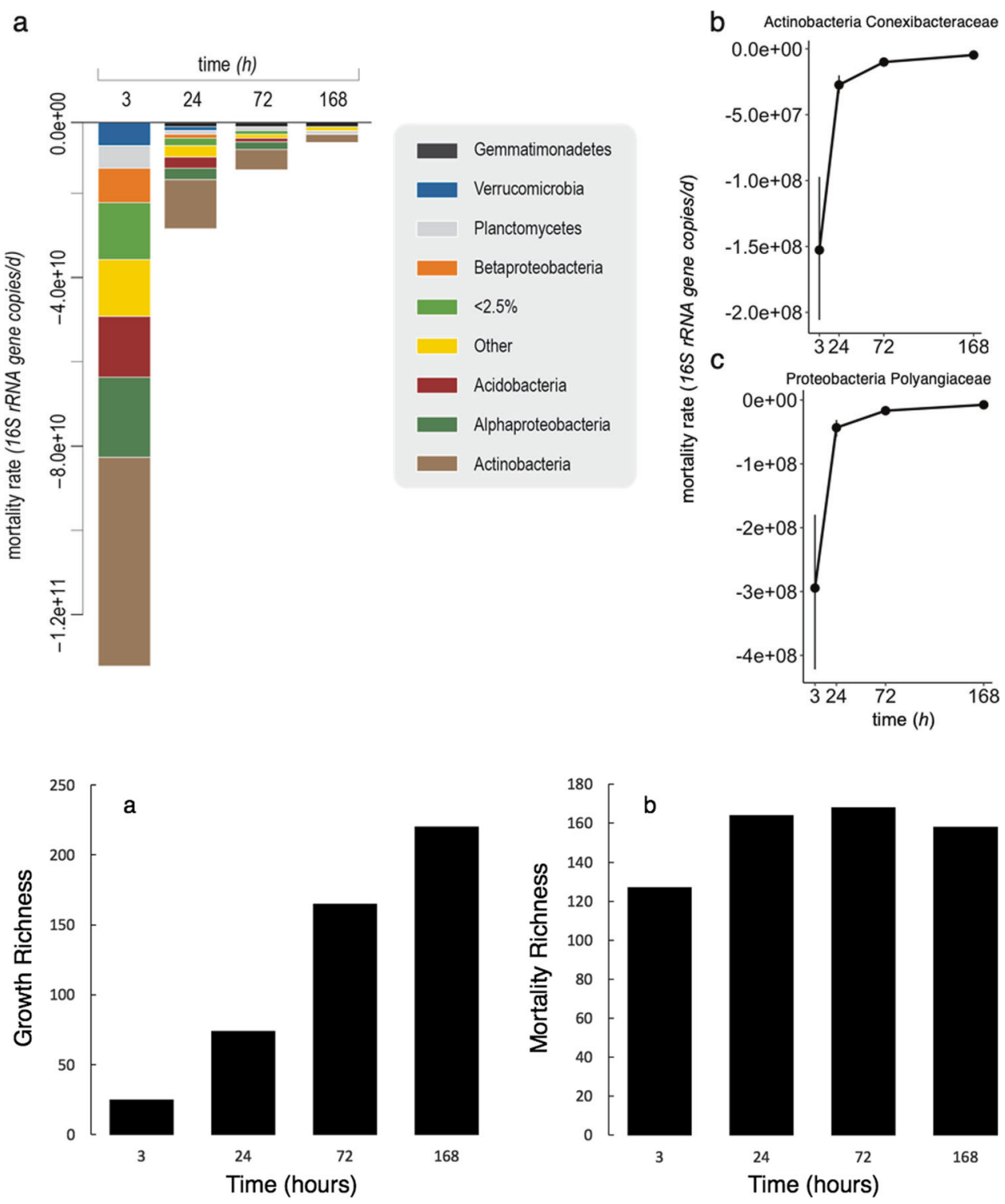

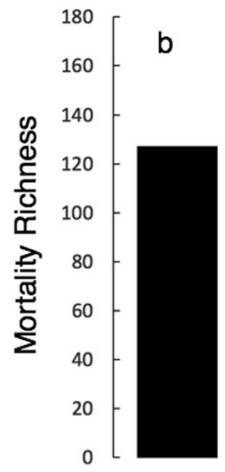

3

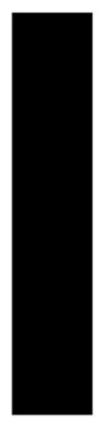

24 Time (hours)

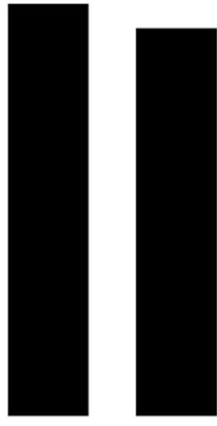

168

\section{Carbon mineralization}

$\mathrm{CO}_{2}$ production was measured as an indicator of microbial activity. Approximately $50 \%$ of the cumulative $\mathrm{CO}_{2}$ produced during the 1-week incubation was released within the first $24 \mathrm{~h}$ (Fig. 4a). The proportion of total $\mathrm{CO}_{2}$ produced at each time point was highly correlated with the community growth rate (Fig. 4b).

\section{Density independent mortality, density dependent growth}

Across bacterial taxa, per capita population growth rates declined as population sizes increased (Fig. 5a). This relationship was apparent even during the first $3 \mathrm{~h}$, and is consistent with negative density dependence, a common phenomenon in population ecology. In contrast, bacterial mortality was density-independent (Fig. 5b): rates of mortality did not significantly vary with population size.

\section{Discussion}

Rewetting of a dry California grassland soil was followed by dynamic growth and death of multiple bacterial populations (Figs. 1, 2). The qSIP approach detected and quantified growth within $3 \mathrm{~h}$; at the order level, the highest absolute population growth rates were observed in the Bacillales $\left(4.2 \times 10^{8}\right.$ rRNA gene copies $\left./ \mathrm{g}_{\text {soil }} / \mathrm{d}\right)$ and Burkholderiales $\left(2.6 \times 10^{8} \mathrm{rRNA}\right.$ gene copies $\left./ \mathrm{g}_{\text {soi }} / \mathrm{d}\right)$ orders in the Firmicutes and Proteobacteria phyla respectively. We note that this increase in growth was detected based on changes in ${ }^{18} \mathrm{O}$ incorporation, and so is the result of new growth detected isotopically, not a "relative abundance 
Fig. $4 \mathrm{CO}_{2}$ production dynamics following wet-up. a The proportion of cumulative $\mathrm{CO}_{2}$ produced during different time periods following a wet-up event in a dry CA annual grassland soil, compared to the total $\mathrm{CO}_{2}$ produced during the week-long incubation. Error bars show standard deviation $(n=3)$. b Correlation between the proportion of $\mathrm{CO}_{2}$ produced vs. community growth rate.

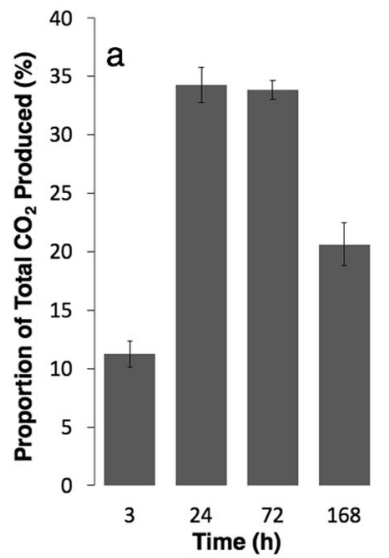

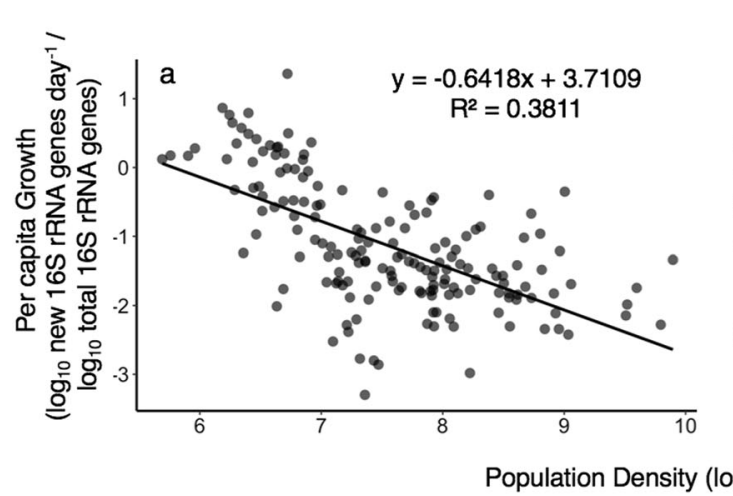

Fig. 5 Relationship between per capita growth and mortality rates and population density following wet-up. Per capita growth (a) and mortality (b) rates as a function of organism density for each taxonomic group during the $0-3 \mathrm{~h}$ time interval. Densities are numbers of copies of the $16 \mathrm{~S}$ gene for a given taxon, per gram soil. Per capita growth and mortality are growth or death rates of taxon-specific $16 \mathrm{~S}$

artifact" commonly found in sequence data and caused by decreased abundance of other taxa. Many Bacillales are spore formers, and it is likely these organisms were present in the prewet soil in a protected state. As spores, they would have been protected during both the long dry down period and the rapid change in water potential associated with wetup. Since spores can germinate on the order of minutes $[56,57]$, once the water potential equilibrated, they may have quickly germinated and begun to grow. However, after the initial $24 \mathrm{~h}$ burst of rapid growth, Firmicutes growth significantly decreased.

The rapid growth of Bacillales and Burkholderia is consistent with the facts that they grow rapidly in culture and they were found to be fast growers under high $\mathrm{C}$ conditions in a cross-ecosystem comparison of soil growth rates [58]. Bacillales were also found to be rapid responders following the wet-up of desert biological soil crusts [59]. The ability to quickly respond may give taxa in these phyla a competitive advantage following disturbances, analogous to ruderal plant species. This life strategy would poise them
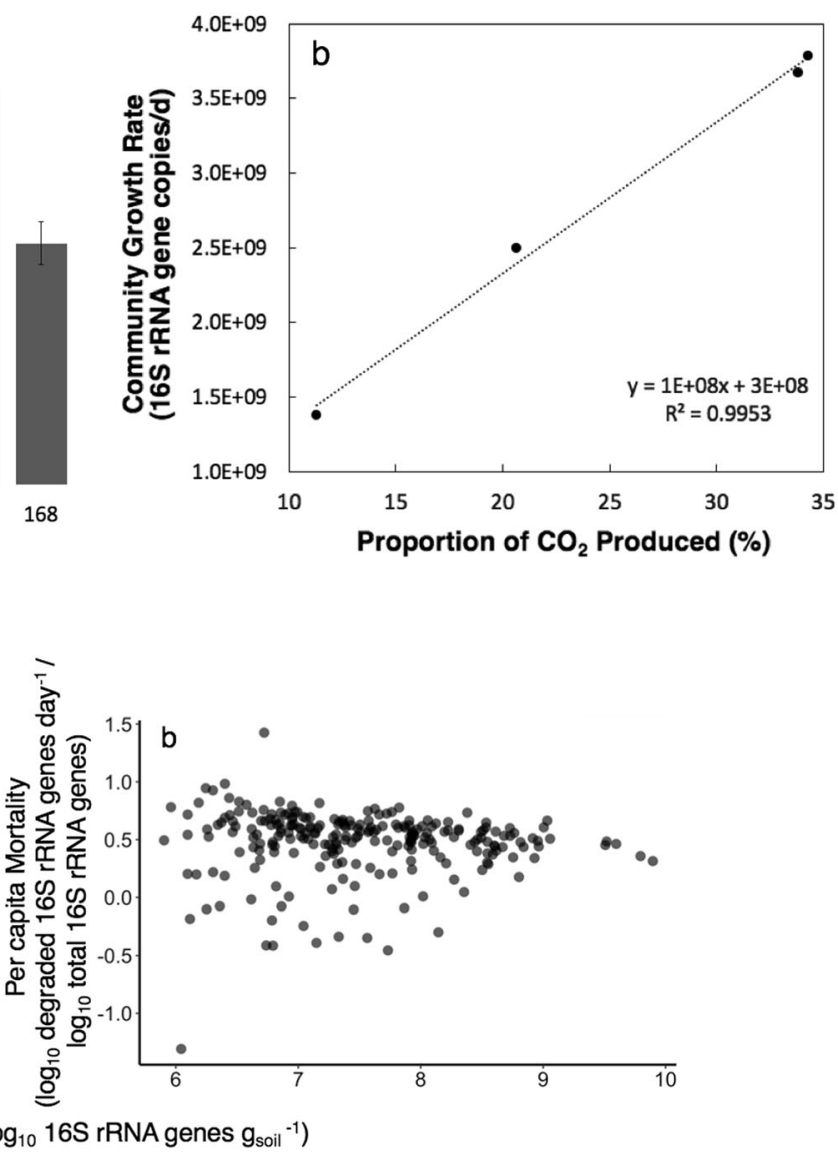

genes per hour per gram soil (as determined by the qSIP pipeline), normalized by taxon-specific abundance. The ecological analog is per capita population growth, dN/Ndt. All rates are log-transformed (base 10). Mortality rates are expressed as positive values to allow log transformation. The regression line for the relationship with growth is significant $(P<0.001)$, but not for mortality $(P=0.68)$

to be among the first taxa to take advantage of the resource pulse that accompanies the wet-up of dry soil.

The highest taxon-specific growth rates were found in the Alphaproteobacteria $\left(1 \times 10^{9} 16 \mathrm{~S}\right.$ rRNA gene copies $/ \mathrm{g}_{\text {soil }} / \mathrm{d}$ at 24 and $72 \mathrm{~h})$ and Betaproteobacteria $\left(1.6 \times 10^{9}\right.$ rRNA gene copies/g $/ \mathrm{g}_{\text {soil }} / \mathrm{d}$ at $24 \mathrm{~h}$ ). Strong responses of Alphaproteobacteria and Betaproteobacteria have also been observed in response to soil wet-up in other soils $[2,36,60]$. The growth of individual bacterial populations followed a sequential pattern (Fig. 1), with relatively few organisms in the "primary responder" category, followed by a steady increase in the number and diversity of growing taxa with time (Figs. 1, 3). This pattern is congruent to what has been observed for bacterial communities during primary succession with an increase in taxonomic diversity over time [61]. A mechanistic explanation for this pattern could be that some taxa have short lag phases driven by the capacity to detect favorable environmental conditions and initiate growth quickly, while other taxa need longer to initiate growth [62]. Perhaps there are trade-offs between 
optimizing lag phase and increasing max growth rate that can influence the outcome of competition.

Distinct growth responses were observed with the majority of taxa classified as tertiary (within 3 days) or delayed (within 1 week) responders (Fig. 1b-e, Table S3). Studying bacteria at higher levels of taxonomy than species can integrate and reduce the immense diversity commonly found in soil $[63,64]$, perhaps leading to a more practical approach for understanding ecosystem function and fitness. Many high taxonomic levels of bacteria, even up to the phylum level, have shown evidence of ecological coherence where members of specific groups share characteristic life strategies that are distinct from other groups [2, 65-67]. Due to the extensive diversity of bacteria, ecological coherence will likely not be universal within a group and may not be observed at the same level of taxonomy for all bacterial lineages, but as demonstrated here, this approach has potential to identify general unifying traits or life strategies that provide insight into connections between community composition and ecosystem functioning.

In contrast to growth, the highest absolute population mortality rates were observed within $3 \mathrm{~h}$ of wet-up. Mortality during this initial timepoint was measured within more phyla compared to growth (Fig. 2a), and mortality richness was much more consistent than growth richness throughout the incubation (Figs. 3, 4). Also in contrast to growth, mortality was dominated by a single response pattern for almost all taxa (Fig. 2b, c) -a sharp increase in the first $3 \mathrm{~h}$, followed by only minor differences in rate for the remainder of the week. Population dynamics can be categorized as densitydependent or density-independent processes; densitydependent processes are primarily regulated by biotic factors such as predation, competition, and the accumulation of metabolic byproducts, whereas density-independent processes are predominantly controlled by abiotic and environmental influences such as disturbance (e.g., fire, freeze, etc.). Following wet-up, we observed the highest rates of mortality during the first $3 \mathrm{~h}$ and measured overall evidence of densityindependent mortality (Fig. 5b), supporting the idea that the rapid initial mortality is likely due to the environmental disturbance of a rapid change in water potential [1], or to decomposition of extracellular DNA accumulated from dying cells throughout the dry season [68].

We expected density-dependent mortality to become apparent over time, as the influence of osmotic shock diminished, and as other, density-dependent drivers of mortality became more important (viruses, predation). However, per capita rates of mortality were consistently flat as a function of population densities (data not shown). Possibly, the mortality caused by osmotic shock was large enough that it masked the influences of these other factors, even when integrating per capita rates of mortality over the entire experimental period. In contrast to mortality, per capita growth rates exhibited negative density-dependence (Fig. 5a), which can occur if resource limitation leads to competition, such that populations with higher densities exhibit slower per capita population growth rates. This suggests that even if wet-up events in soils cause a pulse of increased resource availability, bacterial growth is rapid enough that competition structures the community, even within the first $3 \mathrm{~h}$.

Compared with our past work where we documented density-dependent mortality, likely associated with competition over a 10-day period [16], rates of mortality measured here were substantially higher and over a shorter time period. It is likely that the shorter time-interval favored densityindependent agents of mortality, such as cell lysis associated with the wet-up event. In contrast, the 10-day measurement period used in the earlier study [16] may have been long enough for density-dependent processes, such as competition, to emerge as the dominant signal. Densitydependence and independence are not mutually exclusive, but discovering conditions under which one relationship dominates can shed light on the importance of ecological processes in structuring microbial communities. These results suggest that mortality and growth have distinct regulators with growth more closely linked to life strategies and density-dependent processes, while mortality is regulated more by density-independent processes.

Note that for this work, we define mortality as the disappearance of gene copies since this corresponds with degradation of dead cells. However, it is probable that our measurements integrate both cell death and turnover of previously non-viable DNA. It is likely that cells died immediately following wet-up as a result of rapid change in water potential induced plasmoptysis. It is also likely that cells died during the soil dry-down, but the DNA remain intact due to the extremely low water potential conditions, and degradation of the DNA from cells that died before wetup was only measurable following wet-up when the water potential became more favorable to enzymatic activity.

As a quantitative agent of the mortality of living beings, the annual cycle of summer drought and fall wet-up in California annual grasslands is 18 orders of magnitude larger than the most intense drought event over the past 1200 years, which caused the death of $1 \times 10^{8}$ trees throughout the entire state [69]. In our experiment, wet-up of a single gram of soil caused the death of $2.4 \times 10^{10}$ bacteria per hour (this calculation assumes an average of six copies of the 16S rRNA gene per cell). Scaled up to the grasslands of California (5.64 M hectares), the first rain after the dry summer kills $1.5 \times 10^{26}$ cells in an hour. Across the spectrum of natural disturbance events that result in mortality, we expect this qualifies as among the more extreme.

While being able to characterize community level and taxon-specific growth and mortality curves in soil is a major 
innovation in microbial ecology, it is important to identify ways to utilize this information to better understand biogeochemical processes driven by microbial activities. Average community growth rate was highly correlated with the proportion of total $\mathrm{CO}_{2}$ released through each time period (Fig. 4b). Biological predictors of the Birch effect [3] are challenging to identify, so it is exciting to observe a clear linear relationship between microbial growth rate and $\mathrm{CO}_{2}$ efflux. Despite the promise to inform ecosystem functioning, we are still hard-pressed to identify strong relationships between the vast amounts of molecular data from the now-mature -omics revolution and realized biogeochemical process rates. Our work demonstrates that microbial growth rates can inform predictions of soil $\mathrm{C}$ processing, a critical regulator of ecosystem $\mathrm{C}$ storage. While this is perhaps not surprising, it supports an important step forward in our efforts to improve our ability to apply molecular information in order to understand the impact of microbial activities on their surrounding environment. This further supports the potential for qSIPderived population metrics to enable mechanistic linkages between $\mathrm{C}$ cycling dynamics and soil microbiome community dynamics.

In conclusion, bacterial growth response to a punctuated environmental change followed distinct growth response patterns while mortality was much more uniform. Importantly, these patterns were observable at a high taxonomic level, suggesting ecological coherence in growth response at the phylum. Mortality exhibited density-independence, consistent with the abiotic shock caused by wet-up, whereas growth was density-dependent, consistent with control by competition and predation. Total aggregated growth across the community was correlated with total soil $\mathrm{CO}_{2}$ production. Together, these results hold promise for the idea that, even in complex microbial communities, population dynamics can translate quantitatively to ecosystem-scale biogeochemistry.

Acknowledgements SJB and this experiment were supported by a National Science Foundation Graduate Research Fellowship and a National Science Foundation Doctoral Dissertation Improvement Grant No. DEB-1011093 to UCB. Additional support for analyses and data integration was provided by the US Department of Energy, Office of Biological and Environmental Research, Genomic Science Program LLNL "Microbes Persist” Scientific Focus Area (award \#SCW1632), and award \#DE DE-SC0016207 at Northern Arizona University. Work conducted at LLNL was contributed under the auspices of the US Department of Energy under Contract DE-AC52-07NA27344, and at the Lawrence Berkeley National Laboratory through Contract No. DEAC02-05CH11231.

\section{Compliance with ethical standards}

Conflict of interest The authors declare that they have no conflict of interest.
Publisher's note Springer Nature remains neutral with regard to jurisdictional claims in published maps and institutional affiliations.

\section{References}

1. Kieft T, Soroker E, Firestone M. Microbial biomass response to a rapid increase in water potential when dry soil is wetted. Soil Biol Biochem. 1987;19:119-26.

2. Placella SA, Brodie EL, Firestone MK. Rainfall-induced carbon dioxide pulses result from sequential resuscitation of phylogenetically clustered microbial groups. Proc Natl Acad Sci USA. 2012;109:10931-6.

3. Birch $\mathrm{H}$. The effect of soil drying on humus decomposition and nitrogen availability. Plant Soil. 1958;10:9-31.

4. Unger S, Máguas C, Pereira JS, David TS, Werner C. The influence of precipitation pulses on soil respiration-Assessing the "Birch effect" by stable carbon isotopes. Soil Biol Biochem. 2010;42:1800-10.

5. Fierer N, Schimel J. Effects of drying-rewetting frequency on soil carbon and nitrogen transformations. Soil Biol Biochem. 2002;34:777-87.

6. Schimel J, Jackson L, Firestone M. Spatial and temporal effects on plant-microbial competition for inorganic nitrogen in a California annual grassland. Soil Biol Biochem. 1989;21:1059-66.

7. Davidson EA. Sources of nitric oxide and nitrous oxide following wetting of dry soil. Soil Sci Soc Am J. 1992;56:95-102.

8. Barnard RL, Osborne CA, Firestone MK. Responses of soil bacterial and fungal communities to extreme desiccation and rewetting. ISME J. 2013;7:2229-41.

9. Hungate BA, Lund CP, Pearson HL, Chapin III FS. Elevated $\mathrm{CO}_{2}$ and nutrient addition after soil $\mathrm{N}$ cycling and $\mathrm{N}$ trace gas fluxes with early season wet-up in a California annual grassland. Biogeochemistry. 1997;37:89-109.

10. Schimel JP. Life in dry soils: effects of drought on soil microbial communities and processes. Annu Rev Ecol Evol Syst. 2018;49:409-32.

11. Xu L, Baldocchi DD, Tang J. How soil moisture, rain pulses, and growth alter the response of ecosystem respiration to temperature. Glob Biogeochem Cycles. 2004;18:GB4002.

12. Fierer N, Schimel JP, Holden PA. Influence of drying-rewetting frequency on soil bacterial community structure. Micro Ecol. 2003;45:63-71.

13. Barnard RL, Osborne CA, Firestone MK. Changing precipitation pattern alters soil microbial community response to wet-up under a Mediterranean-type climate. ISME J. 2015;9:946-57.

14. Korem T, Zeevi D, Suez J, Weinberger A, Avnit-Sagi T, PompanLotan $\mathrm{M}$, et al. Growth dynamics of gut microbiota in health and disease inferred from single metagenomic samples. Science. 2015;349:1101-6.

15. Brown CT, Olm MR, Thomas BC, Banfield JF. Measurement of bacterial replication rates in microbial communities. Nat Biotechnol. 2016;34:1256-63.

16. Koch BJ, McHugh TA, Hayer M, Schwartz E, Blazewicz SJ, Dijkstra $\mathrm{P}$, et al. Estimating taxon-specific population dynamics in diverse microbial communities. Ecosphere. 2018;9:e02090-15.

17. Hungate BA, Mau RL, Schwartz E, Caporaso JG, Dijkstra P, van Gestel N, et al. Quantitative microbial ecology through stable isotope probing. Appl Environ Microbiol. 2015;81:7570-81.

18. Pritchard JR, Schluter D. Declining interspecific competition during character displacement: summoning the ghost of competition past. Evol Ecol Res. 2001;3:209-20.

19. Reich PB, Walters MB, Ellsworth DS. From tropics to tundra: global convergence in plant functioning. Proc Natl Acad Sci USA. 1997;94:13730-4. 
20. Schimel D. Terrestrial ecosystems and the carbon cycle. Glob Change Biol. 1995;1:77-91.

21. Tilman D. Resource competition between plankton algae: an experimental and theoretical approach. Ecology. 1977;58:338-48.

22. Morris WF, Doak DF. Quantitative conservation biology: theory and practice of population viability analysis. Sunderland, MA: Sinauer Associates; 2002.

23. Chapin III FS, Walker LR, Fastie CL, Sharman LC. Mechanisms of primary succession following deglaciation at Glacier Bay, Alaska. Ecol Monogr. 1994;64:149-75.

24. Nicholson AJ. The balance of animal populations. J Anim Ecol. 1933;2:132-78.

25. Andrewartha HG, Birch LC. The distribution and abundance of animals. Chicago: University of Chicago Press; 1954.

26. Egerton FN. Changing concepts of the balance of nature. Quart Rev Biol. 1973;48:322-50.

27. Rousk J, Bååth E. Growth of saprotrophic fungi and bacteria in soil. FEMS Microbiol Ecol. 2011;78:17-30.

28. Newell SY, Fallon RD. Toward a method for measuring instantaneous fungal growth rates in field samples. Ecology. 1991;72:1547-59.

29. Poulsen L, Ballard G, Stahl D. Use of rRNA fluorescence in situ hybridization for measuring the activity of single cells in young and established biofilms. Appl Environ Microbiol. 1993;59:1354.

30. Muttray AF, Yu Z, Mohn WW. Population dynamics and metabolic activity of Pseudomonas abietaniphila BKME-9 within pulp mill wastewater microbial communities assayed by competitive PCR and RT-PCR. FEMS Microbiol Ecol. 2001;38:21-31.

31. Blazewicz SJ, Barnard RL, Daly RA, Firestone MK. Evaluating rRNA as an indicator of microbial activity in environmental communities: limitations and uses. ISME J. 2013;7:2061-8.

32. DeAngelis KM, Wu CH, Beller HR, Brodie EL, Chakraborty R, DeSantis TZ, et al. PCR amplification-independent methods for detection of microbial communities by the high-density microarray PhyloChip. Appl Environ Microbiol. 2011;77:6313-22.

33. Gaidos E, Rusch A, Ilardo M. Ribosomal tag pyrosequencing of DNA and RNA from benthic coral reef microbiota: community spatial structure, rare members and nitrogen-cycling guilds. Environ Microbiol. 2011;13:1138-52.

34. Baldrian P, Kolarík M, Stursová M, Kopecky J, Valášková V, Vētrovsky $\mathrm{T}$, et al. Active and total microbial communities in forest soil are largely different and highly stratified during decomposition. ISME J. 2012;6:248-58.

35. Schwartz E. Characterization of growing microorganisms in soil by stable isotope probing with $\mathrm{H}_{2}{ }^{18} \mathrm{O}$. Appl Environ Microbiol. 2007;73:2541-6.

36. Aanderud ZT, Lennon JT. Validation of heavy-water stable isotope probing for the characterization of rapidly responding soil bacteria. Appl Environ Microbiol. 2011;77:4589-96.

37. Blazewicz SJ, Schwartz E. Dynamics of ${ }^{18} \mathrm{O}$ incorporation from $\mathrm{H}_{2}{ }^{18} \mathrm{O}$ into soil microbial DNA. Micro Ecol. 2011;61:911-6.

38. Blazewicz SJ, Schwartz E, Firestone MK. Growth and death of bacteria and fungi underlie rainfall-induced carbon dioxide pulses from seasonally dried soil. Ecology. 2014;95:1162-72.

39. Sambrook J, Russell DW Molecular cloning. A laboratory Manual. 3rd ed. New York: Cold Spring Harbor Laboratory Press; 2001.

40. Buckley DH, Huangyutitham V, Hsu S-F, Nelson TA. Stable isotope probing with ${ }^{15} \mathrm{~N}$ achieved by disentangling the effects of genome $\mathrm{G}+\mathrm{C}$ content and isotope enrichment on DNA density. Appl Environ Microbiol. 2007;73:3189-95.

41. Neufeld JD, Vohra J, Dumont MG, Lueders T, Manefield M, Friedrich MW, et al. DNA stable-isotope probing. Nat Protoc. 2007;2:860-6.

42. Caporaso JG, Lauber CL, Walters WA, Berg-Lyons D, Lozupone $\mathrm{CA}$, Turnbaugh PJ, et al. Global patterns of $16 \mathrm{~S}$ rRNA diversity at a depth of millions of sequences per sample. Proc Natl Acad Sci USA. 2011;108:4516-22.

43. Bolger AM, Lohse M, Usadel B. Trimmomatic: a flexible trimmer for Illumina sequence data. Bioinformatics. 2014;30:2114-20.

44. Lohse M, Bolger AM, Nagel A, Fernie AR, Lunn JE, Stitt M, et al. RobiNA: a user-friendly, integrated software solution for RNA-Seq-based transcriptomics. Nucleic Acids Res. 2012;40: W622-W7.

45. Edgar RC. Search and clustering orders of magnitude faster than BLAST. Bioinformatics. 2010;26:2460-1.

46. Caporaso JG, Kuczynski J, Stombaugh J, Bittinger K, Bushman FD, Costello EK, et al. QIIME allows analysis of high-throughput community sequencing data. Nat Methods. 2010;7:335-6.

47. Wang Q, Garrity GM, Tiedje JM, Cole JR. Naive Bayesian classifier for rapid assignment of rRNA sequences into the new bacterial taxonomy. Appl Environ Microbiol. 2007;73:5261-7.

48. Desantis TZ, Hugenholtz P, Larsen N, Rojas M, Brodie EL, Keller $\mathrm{K}$, et al. Greengenes, a chimera-checked 16S rRNA gene database and workbench compatible with ARB. Appl Environ Microbiol. 2006;72:5069-72.

49. Caporaso JG, Bittinger K, Bushman FD, Desantis TZ, Andersen GL, Knight R. PyNAST: a flexible tool for aligning sequences to a template alignment. Bioinformatics. 2010;26:266-7.

50. Edgar RC, Haas BJ, Clemente JC, Quince C, Knight R. UCHIME improves sensitivity and speed of chimera detection. Bioinformatics. 2011;27:2194-200.

51. Schildkraut CL, Marmur J, Doty P. Determination of the base composition of deoxyribonucleic acid from its buoyant density in CsCl. J Mol Biol. 1962;4:430-43.

52. Martin-Laurent F, Phillipot L, Hallet S, Chaussod R, Germon JC, Soulas G, et al. DNA extraction from soils: old bias for new microbial diversity analysis methods. Appl Environ Microbiol. 2001;67:2354-59.

53. Kanagawa T. Bias and artifacts in multitemplate polymerase chain reactions (PCR). J Biosci Bioeng. 2003;96:317-23.

54. Kozarewa I, Ning Z, Quail MA, Sanders MJ, Berriman M, Turner DJ. Amplification-free Illumina sequencing-library preparation facilitates improved mapping and assembly of $(\mathrm{G}+\mathrm{C})$-biased genomes. Nat Methods. 2009;6:291-5.

55. R Core Team. R: A language and environment for statistical computing. R Foundation for Statistical Computing, Vienna, Australia 2016. http://www.R-project.org/.

56. Hashimoto T, Frieben WR, Conti SF. Germination of single bacterial spores. J Bacteriol. 1969;98:1011-20.

57. Levinson HS, Hyatt MT. Correlation of respiratory activity with phases of spore germination and growth in bacillus megaterium as influenced by manganese and L-alanine. $\mathrm{J}$ Bacteriol. 1956;72:176-83.

58. Morrissey EM, Mau RL, Hayer M, Liu XJ, Schwartz E, Dijkstra $\mathrm{P}$, et al. Evolutionary history constrains microbial traits across environmental variation. Nat Ecol Evol. 2019;3:1064-9.

59. Karaoz U, Couradeau E, da Rocha UN, Lim HC, Northen T, Garcia-Pichel F, et al. Large blooms of bacillales (Firmicutes) underlie the response to wetting of cyanobacterial biocrusts at various stages of maturity. MBio. 2018;9:e01366-16-17.

60. Engelhardt IC, Welty A, Blazewicz SJ, Bru D, Rouard N, Breuil MC, et al. Depth matters: effects of precipitation regime on soil microbial activity upon rewetting of a plant-soil system. ISME J. 2018;12:1061-71.

61. Ortiz-Álvarez R, Fierer N, de los Ríos A, Casamayor EO, Barberan A. Consistent changes in the taxonomic structure and functional attributes of bacterial communities during primary succession. ISME J. 2018;12:1658-67.

62. Adkar BV, Manhart M, Bhattacharyya S, Tian J, Musharbash M, Shakhnovich EI. Optimization of lag phase shapes the evolution of a bacterial enzyme. Nat Ecol Evol. 2017;1:8396-18. 
63. Gans J, Wolinsky M, Dunbar J. Computational improvements reveal great bacterial diversity and high metal toxicity in soil. Science. 2005;309:1387-90.

64. Curtis TP, Sloan WT. Exploring microbial diversity-a vast below. Science. 2005;309:1331-3.

65. Philippot L, Andersson GE, Battin TJ, Prosser JI, Schimel JP, Whitman WB, et al. The ecological coherence of high bacterial taxonomic ranks. Nat Rev Micro. 2010;8:523-9.

66. Philippot L, Bru D, Saby NPA, Čuhel J, Arrouays D, Šimek M, et al. Spatial patterns of bacterial taxa in nature reflect ecological traits of deep branches of the 16S rRNA bacterial tree. Environ Microbiol. 2009;11:3096-104.
67. Fierer N, Bradford MA, Jackson RB. Toward an ecological classification of soil bacteria. Ecology. 2007;88:1354-64.

68. Morrissey EM, McHugh TA, Preteska L, Hayer M, Dijkstra P, Hungate BA, et al. Dynamics of extracellular DNA decomposition and bacterial community composition in soil. Soil Biol Biochem. 2015;86:42-9.

69. USDA Office of Communications. New aerial survey identifies more than 100 million dead trees in California. 2016. https://www. usda.gov/media/press-releases/2016/11/18/new-aerial-surveyidentifies-more-100-million-dead-trees-california. 